\title{
Revisiting the incorporation of Ti(IV) in UiO-type metal-organic frameworks: metal exchange versus grafting and their implications on photocatalysis
}

Jara G. Santaclara, ${ }^{\dagger}$ Alma I. Olivos-Suarez, ${ }^{\dagger,}{ }^{*}$ Adrian Gonzalez-Nelson, ${ }^{\dagger}$ Dmitrii Osadchii, ${ }^{\dagger, \#}$ Maxim A. Nasalevich, ${ }^{\dagger}$ Monique A. van der Veen, ${ }^{\dagger}$ Freek Kapteijn, ${ }^{\dagger}$ Alena M. Sheveleva, ${ }^{\ddagger}$ Sergey L. Veber, ${ }^{\ddagger}$ Matvey V. Fedin, ${ }^{\ddagger}$ Alexander T. Murray, ${ }^{\S,}{ }^{*}$ Christopher H Hendon, " ," Aron Walsh ${ }^{\perp}$ and Jorge Gascon ${ }^{\dagger, \#, *}$

${ }^{\dagger}$ Catalysis Engineering, Department of Chemical Engineering. Delft University of Technology van der Maasweg 9, 2629 HZ, Delft, The Netherlands.

${ }^{\#}$ King Abdullah University of Science and Technology, KAUST Catalysis Center, Advanced Catalytic Materials, Thuwal 23955, Saudi Arabia.

${ }^{\ddagger}$ International Tomography Center, Novosibirsk 63009o, Russia. Novosibirsk State University, Novosibirsk 630ogo, Russia.

${ }^{\S}$ Department of Chemistry, Massachusetts Institute of Technology, Cambridge, MA, o2139 USA.

"Department of Chemistry and Biochemistry, University of Oregon, Eugene, OR, 97403, USA.

${ }^{\perp}$ Department of Materials, Imperial College London, London, $S W_{7} 2 A Z$, UK. Global E ${ }^{3}$ Institute and Department of Materials Science and Engineering, Yonsei University, Seoul 120-749, South Korea.

\begin{abstract}
The inclusion of Ti(IV) in water-stable metal-organic frameworks has been proposed as a strategy for the generation of high surface area heterogeneous photocatalysts, with UiO-66 being a promising candidate. We find that the site of binding of $\mathrm{Ti}(\mathrm{IV})$ is at linker defect sites and not incorporated into the inorganic secondary building unit through metal exchange. We also demonstrate the choice of titanium source is critical in the generation of an active hydrogen evolution catalyst, and explain the observed activity using density functional theory calculations, which also enable rational design of future Ti(IV) coordination environments in MOF catalysts.
\end{abstract}

\section{Introduction}

The generation of hydrogen from water (hydrogen evolution reaction - HER) mediated by sunlight is a key challenge in the design of new energy conversion paradigms. While there are many classes of materials that will promote this reaction, metal-organic frameworks (MOFs) have emerged as promising platforms, owing to their high surface area, structural diversity and late-stage tunability. ${ }^{2}$ However, most MOFs suffer from hydrolytic instability, limiting their application in aqueous HER photocatalytic systems. ${ }^{3,4}$ MOFs of the UiO series possess good water and thermal stability, and opportunities for postsynthetic modification.,

Common strategies for functionalisation of Zr-UiO-type materials include linker modification and metal incorporation. ${ }^{7-9}$ The former has been extensively studied in both UiO- and MIL-125-type materials through utilisation of functionalised ligands. ${ }^{10}{ }^{-12}$ For example, amination of the terephthalic acid linker in MIL-125 has been shown to close the band gap, redshifting from the UV and thus enabling visible light photocatalysis. In the case of UiO66 , the addition of $\mathrm{Ti}(\mathrm{IV})$ has been extensively studied because of its photoaccessible unoccupied Ti(III) state, but nevertheless the structural characterization of these materials remains largely unknown. ${ }^{13-18}$

The two hypotheses for how incorporation of Ti into UiO-66 occurs are either through metal exchange into the inorganic secondary building unit (SBU), or grafting of the $\mathrm{Ti}(\mathrm{IV})$ onto the surface of this node at a linker vacancy site (Figure 1). Metal exchange has been attempted primarily with $\mathrm{TiCl}_{4} \cdot 2 \mathrm{THF}$ as a $\mathrm{Ti}(\mathrm{IV})$ source, but the nature of this exchange is inconclusive. ${ }^{8,14,19-21}$ 

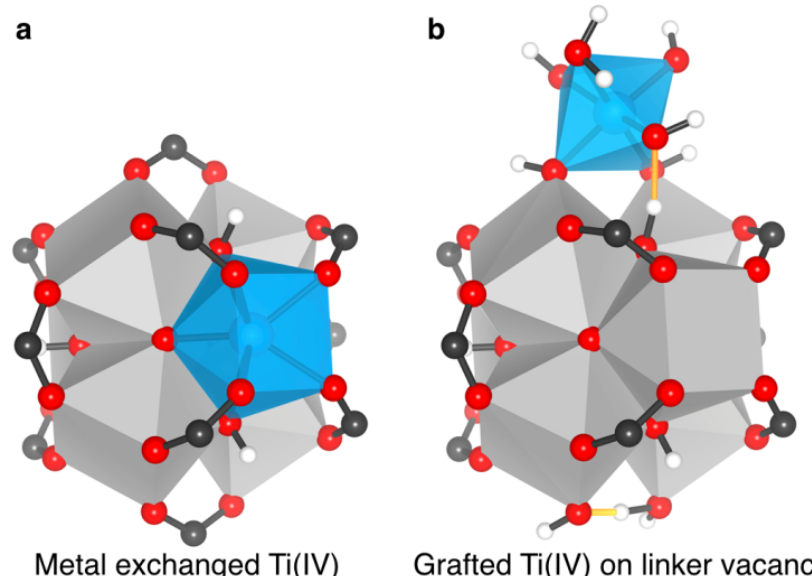

Grafted Ti(IV) on linker vacancy

Figure 1. Proposed coordination sites of Ti in UiO-type materials. (a) The inclusion of $\mathrm{Ti}(\mathrm{IV})$ in the cluster through metal exchange. (b) The appendage of Ti(IV) to the surface of the cluster at a linker vacancy defect site.

A major impediment to the understanding of metal inclusion in UiO-type materials, either as ion exchange or metal appendage, is that while Ti(IV) can also be conjectured to occupy linker vacancy sites, until recently the nature of these vacancies was poorly understood. ${ }^{22,23}$ However, recent advances in the characterisation of $\mathrm{UiO}$ defect chemistry has revealed up to $33 \%$ linker vacancies, $^{24-30}$ and the nature of these vacancies has been systematically explored in the related NU-10oo MOF and the MOF-801 series. ${ }^{31,32}$

\section{Results and Discussion}

An ideal Ti(III) photocatalyst features low energy unoccupied $\mathrm{Ti}(\mathrm{IV})$ orbitals that allow facile electron occupation of this state upon photoirradiation, and a local electron rich ligand that can transiently stabilize a proton (e.g. a bridging oxo as found in MIL-125, or pendant hydroxy/alkoxy motif). ${ }^{33,34}$ Hence, DFT calculations are able to systematically elucidate the nature of the frontier bands for different $\mathrm{Ti}$ coordination environments in $\mathrm{UiO}-$ 66. The UiO-66 material's frontier orbitals are defined by a ligand-ligand transition (Figure 2). ${ }^{35}$ Amination of the linker (i.e. $\mathrm{NH}_{2}-\mathrm{UiO}-66(\mathrm{Zr}), \mathbf{1}$ ) yields an occupied midgap state, albeit still with a ligand-based transition (Figure 2). ${ }^{36}$ We then investigated the energies of $\mathrm{Ti}$ both in the cluster (metal exchange) and on a defect site (metal appendage), in both the aminated and native frameworks. When $\mathrm{Ti}$ is incorporated in the cluster, the valence bands are unaltered and the conduction bands do not feature Ti orbitals at the frontier; rather $\mathrm{Ti}$ orbitals are found at marginally higher energies but nevertheless should be photoaccessible. Likewise, with $\mathrm{Ti}$ appended on defect sites the conduction band is not defined primarily by $\mathrm{Ti}$ orbitals.

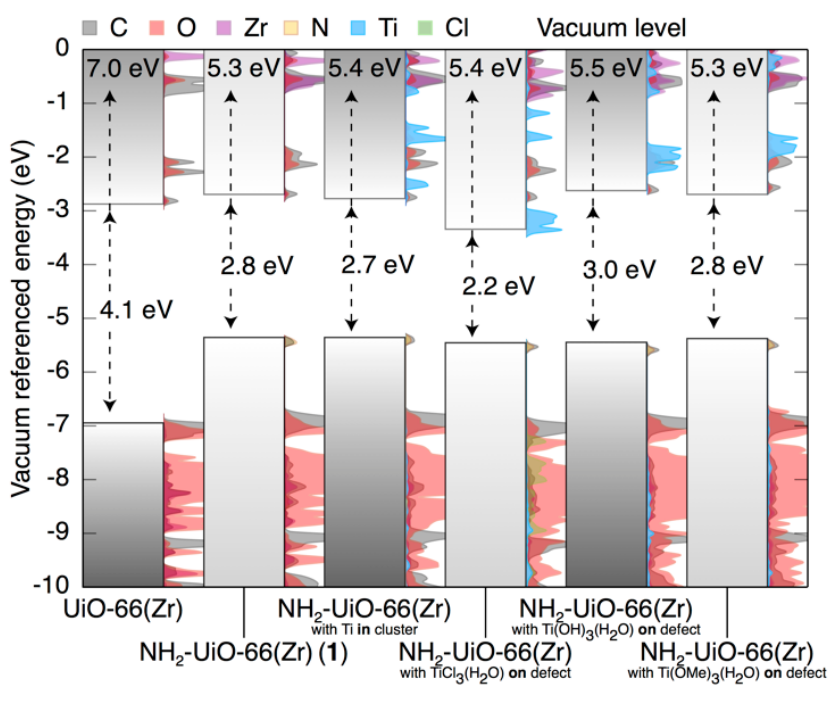

Figure 2. The density of states (DOS) and band alignment of native $\mathrm{Zr}-\mathrm{UiO}-66$, the $16 \%-\mathrm{NH}_{2}-\mathrm{UiO}-66(\mathrm{Zr})$ (1), compared to the models with $\mathrm{Ti}(\mathrm{IV})$ inside the SBU, or appended to the linker defect site and passivated with $\mathrm{Cl}^{-}$, ${ }^{-} \mathrm{OH}$ or ${ }^{-} \mathrm{OMe}$. A single $\mathrm{H}_{2} \mathrm{O}$ is included to complete the octahedral coordination sphere. DOS at $\sim 5.4 \mathrm{eV}$ and $\sim 2.9 \mathrm{eV}$ have aminobenzene parentage.

These calculations assume that additional ligands on titanium are hydroxyl groups. With a weaker-field ligand such as $\mathrm{Cl}^{-}$the $\mathrm{Ti}(\mathrm{IV})$ unoccupied state is stabilized thus bringing $\mathrm{Ti}$ orbitals to the frontier, Figure 2. Therefore, the ligand set as well as the titanium site occupancy should be paramount in generating an active photocatalyst.

As our goal was to generate a visible-light active photocatalyst we used the aminated precursor, 1. Initially, we attempted to functionalize $\mathbf{1}$ with $\mathrm{TiCl}_{4} \cdot \mathbf{2} \mathrm{THF}$ using a method previously reported. ${ }^{8}$ However, the material formed under these conditions, 1', simply featured an increase in linked vacancies as observed by an increase in the BET adsorption isotherm (Figure $\mathrm{S}_{1}, \mathrm{~S}_{2}$ ), and increasing infrared $\mathrm{O}-\mathrm{H}$ stretching anisotropy (Figure $\mathrm{S}_{3}, \mathrm{~S}_{4}$ ). Additionally, we see both $\mathrm{Ti}$ and $\mathrm{Cl}$ inclusion by TEM/EDX (transmission electron microscopy/ energy dispersive X-Ray analysis, Figure $\mathrm{S}_{5}$ ). Given the propensity of $\mathrm{Ti}-\mathrm{Cl}$ bonds to hydrolyse under the synthetic conditions (three days in methanol), we instead suspect $\mathrm{Cl}$ termination of zirconium clusters and formation of $\mathrm{Ti}(\mathrm{OR})_{\mathrm{x}}$ type materials in the pore. Upon photoexcitation of 1', $X / Q$-band EPR (9/34 GHz) indicates electron transfer with a formation of $\mathrm{Ti}(\mathrm{III})$ in octahedral coordination environment, similar to MIL-125- $\mathrm{NH}_{2}$ (Figure 5). However, the observation of sharp peaks with well resolved $g$ tensor components $g=\left[\begin{array}{lll}1.976 & 1.945 & 1.925\end{array}\right]$ is more consistent with a single Ti environment (e.g. Ti(OR) $)_{x}$ ) rather than with the superposition of environments anticipated if Ti would reside at the defect sites (vide infra). 


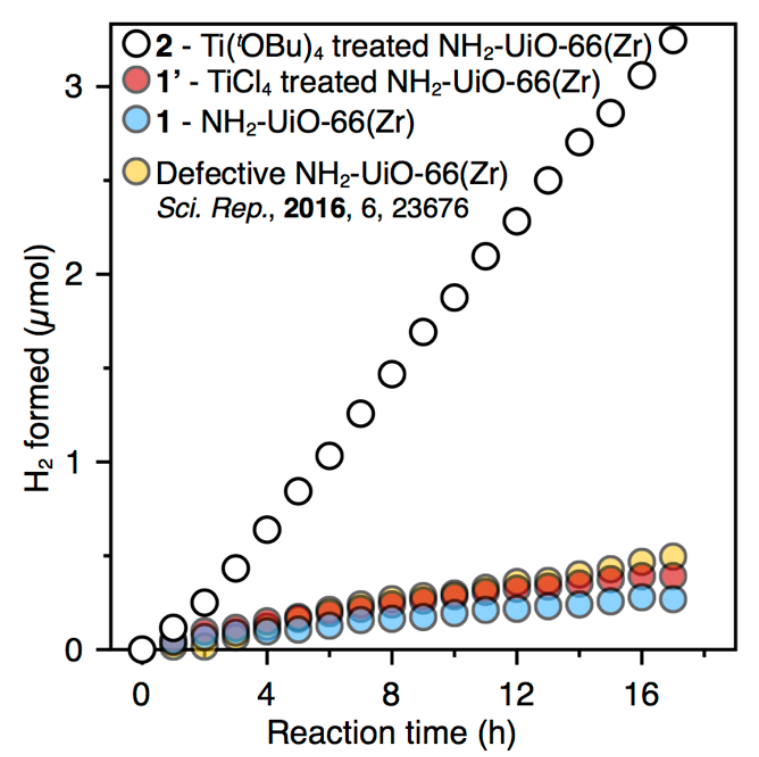

Figure 3. Photocatalytic activity of native $\mathrm{NH}_{2}-\mathrm{UiO}-66(\mathrm{Zr})(\mathbf{1}$, blue) and a deliberately defective analogue (yellow) compared to the $\mathrm{TiCl}_{4}$-loaded $\mathrm{NH}_{2}-\mathrm{UiO}-66(\mathrm{Zr})$ (1', red), and $\mathrm{Ti}\left({ }^{t} \mathrm{OBu}\right)_{4}$-treated $\mathrm{NH}_{2}-\mathrm{UiO}-66(\mathrm{Zr})$ (2, white). Deliberately defective $\mathrm{NH}_{2}-\mathrm{UiO}-66$ was synthesized using the method presented in Ref 35 .

The photocatalytic hydrogen evolution activity of $\mathbf{1}$ ' was found to be $1.5 \mathrm{x}$ greater than native 1 (Figure 3). Indeed, this HER activity is in line with previously reported results for the defect-laden version of this material (data of the deliberately defective $\mathrm{NH}_{2}-\mathrm{UiO}-66(\mathrm{Zr})$ showed a $1.7 \mathrm{x}$ increase in photocatalytic activity, with approximately $30 \%$ linker vacancies). ${ }^{36}$ From this data, we propose that $\mathrm{Ti}$ is not primarily responsible for catalytic activity in this case. Therefore, we developed a new synthetic route to minimize new linker vacancies formed during the metal inclusion.

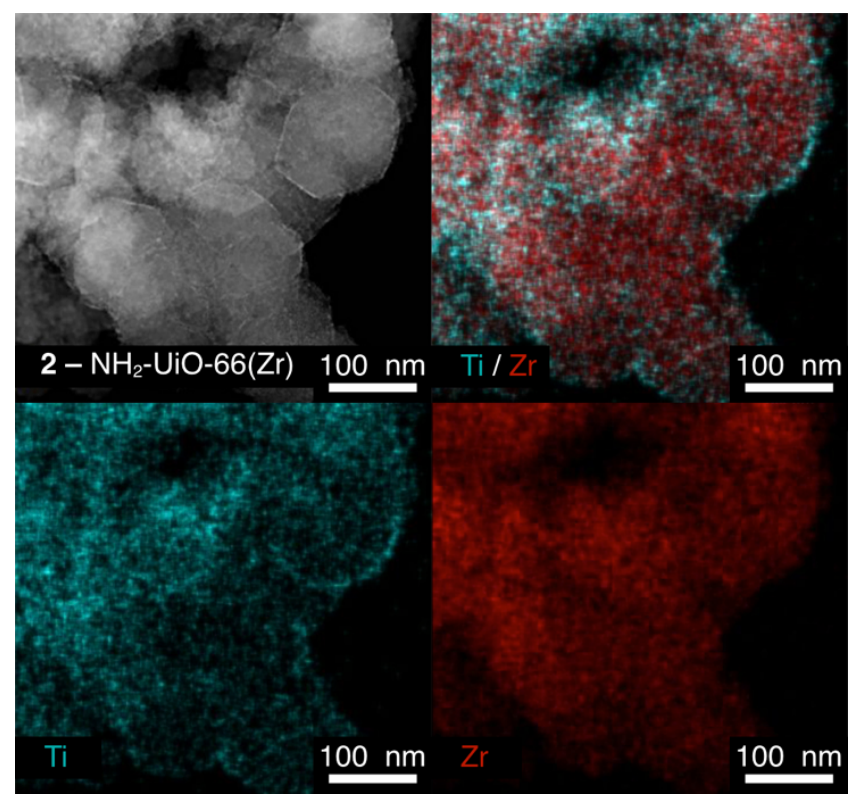

Figure 4. Transmission electron microscopy / energy dispersive $\mathrm{X}$-ray spectroscopy images of $\mathrm{NH}_{2}-\mathrm{UiO}-66(\mathrm{Zr})(\mathbf{2})$. $\mathrm{Ti}(\mathrm{IV})$ is present throughout the crystal, with highest concentrations found on the crystal edges.

The most frequently proposed defect passivation of the zirconia SBUs is through termination with pendant $-\mathrm{OH}$ groups, that share a third proton in a bridging $\mathrm{H}$-bond (depicted at the bottom of Figure $1 b$ ). We propose that use of a more basic Ti salt could deprotonate the defect site and thus enhance grafting of $\mathrm{Ti}$ onto the inorganic SBU. Thus, we selected $\mathrm{Ti}\left(\mathrm{O}^{\mathrm{n}} \mathrm{Bu}\right)_{4}$ as the $\mathrm{Ti}(\mathrm{IV})$ source for post-synthetic modification of $\mathbf{1}$ to form a postulated Tigrafted product referred to as $\mathbf{2}$ (depicted in Figure $1 \mathrm{~b}$ ). Given the reaction conditions, a representative model of the Ti-coordination sphere is likely either octahedral $\mathrm{Ti}(\mathrm{IV})$ with either associated hydroxides or alkoxides. The electronic structure of both systems is presented in Figure 2. 2 demonstrates the expected decrease in BET area, associated with the grafting of the $\mathrm{Ti}(\mathrm{IV})$ to the surface of the SBU, a single IR $\mathrm{O}-\mathrm{H}$ stretching resonance, and a higher proportion of remaining residues of metal oxides observed by TGA (Figure S1, S3, S6) corresponding to the appendage of a metal with no concurrent increase in site vacancies. Importantly, if metal exchange were occurring into the SBU, we would expect no decrease in the surface area.

TEM/EDS mapping of Ti shows good dispersion of $\mathrm{Ti}(\mathrm{IV})$ (Figure 4), with some preference for surface functionalization. EPR of the photoexcited material (X- and Q-band) in this case shows a more diffuse $\mathrm{Ti}^{\mathrm{III}}$ signal relative to 1' (Figure 5), indicative of a broader distribution of $g$-tensor components and suggesting a number of possible combinations of Ti-containing linker defects on $\mathrm{Zr}$ SBUs. Noteworthy, measurements of the T1 and T2 relaxation times of $\mathbf{2}$ are in good agreement for highly dispersed $\mathrm{Ti}(\mathrm{IV})$ through the UiO-66 lattice (Figure S11) and suggest that $\mathrm{Ti}$ is atomically dispersed. Long-range crystallinity appeared to be maintained as observed by PXRD (Figure $\mathrm{S}_{7}$ ).

Most importantly the grafted material, 2, demonstrates significantly improved photocatalysis compared to the other materials considered here. Upon irradiation in $\mathrm{CH}_{3} \mathrm{CN} / \mathrm{Et}_{3} \mathrm{~N} / \mathrm{H}_{2} \mathrm{O}$, hydrogen was evolved from water with a rate of $0.2 \mu \mathrm{mol} \mathrm{h}^{-1}$, attributed to photocatalysis occurring at the $\mathrm{Ti}(\mathrm{III})$ sites, (Figure 3). This corresponds to a rate $14 \mathrm{X}$ greater than either native $\mathrm{NH}_{2}-\mathrm{UiO}-66(\mathrm{Zr})$ (1) or the material formed by $\mathrm{Ti}$ incorporation through treatment of 1 with $\mathrm{TiCl}_{4} \cdot 2 \mathrm{THF}\left(\mathbf{1}^{\prime}\right)$. Indeed, upon photoirradiation of 2 at $370 \mathrm{~nm}$, a new transient absorption band centred at around $750 \mathrm{~nm}$ was observed (Figure S9), which, in agreement with EPR, likely corresponds to a $\mathrm{Ti}(\mathrm{III})$ excitation. ${ }^{37-4^{\circ}}$ 


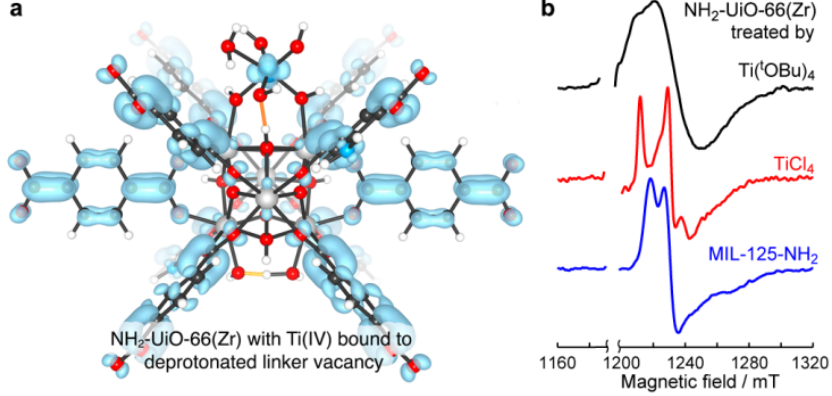

Figure 5. (a) The spin density of the pseudoexcited state of $16 \%-\mathrm{NH}_{2}-\mathrm{UiO}-66(\mathrm{Zr})-\mathrm{Ti}(\mathrm{OH})_{3}\left(\mathrm{H}_{2} \mathrm{O}\right), 2$ shows a majority of spin contribution on the organic linker but, importantly a minor contribution from a Ti(III) d-orbital. The Ti(III) density should increase proportionally with loading on the framework. (b) Q-band continuous wave EPR spectra $(\approx 33.5 \mathrm{GHz})$ of photoexcited MIL-125- $\mathrm{NH}_{2}, \mathbf{1}$ ' and 2 in the reaction mixture of $\mathrm{CH}_{3} \mathrm{CN} / \mathrm{Et}_{3} \mathrm{~N} / \mathrm{H}_{2} \mathrm{O}$.

From direct comparison of the 2-Ti-Cl, $-\mathrm{Ti}-\mathrm{OH}$ and Ti-OMe structures we see that the electron density of the ligand determines the extent of $\mathrm{Ti}$ contribution to the conduction band. Whilst $-\mathrm{Cl}$ termination is electronically the most favorable, it is unlikely that such ligand environments persist under relevant reaction conditions. Despite both $-\mathrm{OH}$ and -OMe terminated models suggesting minimal Ti $d$ orbital contributions to their conduction band minima, the ground state DFT calculation is not the most informative representation of the orbital density upon photoexcitation. Thus, we constructed a model of triple-OH terminated 2 and find that indeed most of the band is defined by the ligands, but there is additional highly localized titanium $d$ character as a minor component (emphasized in Figure 5a). Two conclusions can be drawn from this calculation: i) the titanium density of states will increase proportionally with the increased loading of $\mathrm{Ti}$ in the MOF, and ii) titanium density will increase with proportionally to linker vacancies (either by increased loading of Ti-sites, or by decreased linker contribution to the frontier bands).

\section{Conclusions}

We have found that upon titanium incorporation into the MOF UiO-66, the type of Ti binding is through appendage of $\mathrm{Ti}$ to a linker vacancy rather than replacement of zirconium in the SBU. Careful choice of titanium source in the post-synthetic modification of this MOF determines the extent of covalent interaction between the MOF and Ti. Furthermore, the appendage of Ti(IV) to the surface of the MOF yields a moderately active HER photocatalyst. More active catalysts will likely spawn from the engineering the Ti-bound ligand set to achieve persistence in reaction conditions whilst being weakly electron donating (to lower the $\mathrm{Ti}$ (III) band deeper into the electronic band gap). Therefore, we have shown that in MOF catalyst design both the defect environment and external ligand field are equally important in the further improvement of activity in photocatalysis for this class of materials.

\section{Experimental Section}

Comprehensive experimental details of PXRD, EPR, TEM/EDX, gas sorption isotherms, DRIFTS, diffuse reflectance UV-Vis, DTAS, and computational methods are included in the Supporting Information.

\section{AUTHOR INFORMATION}

\section{Corresponding Author}

*E-mail: a.i.olivossuarez@tudelft.nl

*E-mail: chendon@uoregon.edu

*E-mail: murraya@mit.edu

*E-mail: jorge.gascon@kaust.edu.sa

\section{ACKNOWLEDGMENT}

This work used the Extreme Science and Engineering Discovery Environment (XSEDE), which is supported by National Science Foundation grant number ACI-1053575. S.L.V. and M.V.F. thank the Russian Science Foundation (no. 14-13oo826).

\section{REFERENCES}

1. Tachibana, Y.; Vayssieres, L.; Durrant, J. R., Artificial photosynthesis for solar water-splitting. Nat. Photon. 2012, 6, 511518.

2. Zhang, T.; Lin, W., Metal-organic frameworks for artificial photosynthesis and photocatalysis. Chem. Soc. Rev. 2014, 43, 5982-5993.

3. Nasalevich, M. A.; van der Veen, M.; Kapteijn, F.; Gascon, J., Metal-organic frameworks as heterogeneous photocatalysts: advantages and challenges. CrystEngComm 2014, 16, 4919-4926.

4. Santaclara, J. G.; Kapteijn, F.; Gascon, J.; van der Veen, M. A., Understanding metal-organic frameworks for photocatalytic solar fuel production. CrystEngComm 2017, 19, 4118 - 4125 .

5. Cavka, J. H.; Jakobsen, S.; Olsbye, U.; Guillou, N.; Lamberti, C.; Bordiga, S.; Lillerud, K. P., A New Zirconium Inorganic Building Brick Forming Metal Organic Frameworks with Exceptional Stability. J. Am. Chem. Soc. 2008, 130, 1385013851.

6. Gomes Silva, C.; Luz, I.; Llabrés i Xamena, F. X.; Corma, A.; García, H., Water Stable Zr-Benzenedicarboxylate Metal-Organic Frameworks as Photocatalysts for Hydrogen Generation. Chem. Eur. J. 2010, 16, 11133-11138.

7. Hendrickx, K.; Vanpoucke, D. E. P.; Leus, K.; Lejaeghere, K.; Van Yperen-De Deyne, A.; Van Speybroeck, V.; Van Der Voort, P.; Hemelsoet, K., Understanding Intrinsic Light Absorption Properties of UiO-66 Frameworks: A Combined Theoretical and Experimental Study. Inorg. Chem. 2015, 54, 10701-10710.

8. $\quad$ Kim, M.; Cahill, J. F.; Fei, H.; Prather, K. A.; Cohen, S. M., Postsynthetic Ligand and Cation Exchange in Robust MetalOrganic Frameworks. J. Am. Chem. Soc. 2012, 134, 18082-18088.

9. Marshall, R. J.; Forgan, R. S., Postsynthetic Modification of Zirconium Metal-Organic Frameworks. Eur. J. Inorg. Chem. 2016, 27, 4310-4331.

10. Chavan, S. M.; Shearer, G. C.; Svelle, S.; Olsbye, U.; Bonino, F.; Ethiraj, J.; Lillerud, K. P.; Bordiga, S., Synthesis and Characterization of Amine-Functionalized Mixed-Ligand Metal- 
Organic Frameworks of UiO-66 Topology. Inorg. Chem. 2014, 53, 9509-9515.

11. Hendon, C. H.; Tiana, D.; Fontecave, M.; Sanchez, C.; D'Arras, L.; Sassoye, C.; Rozes, L.; Mellot-Draznieks, C.; Walsh, A., Engineering the Optical Response of the Titanium-MIL-125 Metal-Organic Framework through Ligand Functionalization. J. Am. Chem. Soc. 2013, 135, 10942-10945.

12. Nasalevich, M. A.; Goesten, M. G.; Savenije, T. J.; Kapteijn, F.; Gascon, J., Enhancing optical absorption of metalorganic frameworks for improved visible light photocatalysis. Chem. Commun. 2013, 49, 10575-10577.

13. Lee, Y.; Kim, S.; Kang, J. K.; Cohen, S. M., Photocatalytic $\mathrm{CO}_{2}$ reduction by a mixed metal $(\mathrm{Zr} / \mathrm{Ti})$, mixed ligand metal-organic framework under visible light irradiation. Chem. Commun. 2015, 51, 5735-5738.

14. Yasin, A. S.; Li, J.; Wu, N.; Musho, T., Study of the inorganic substitution in a functionalized UiO-66 metal-organic framework. Phys. Chem. Chem. Phys. 2016, 18, 12748-12754.

15. Sun, D.; Liu, W.; Qiu, M.; Zhang, Y.; Li, Z., Introduction of a mediator for enhancing photocatalytic performance via post-synthetic metal exchange in metal-organic frameworks (MOFs). Chem. Commun. 2015, 51, 2056-2059.

16. Wang, A.; Zhou, Y.; Wang, Z.; Chen, M.; Sun, L.; Liu, $\mathrm{X}$., Titanium incorporated with UiO-66(Zr)-type Metal-Organic Framework (MOF) for photocatalytic application. RSC Adv. 2016, 6, 3671-3679.

17. Brozek, C. K.; Dinca, M., Cation exchange at the secondary building units of metal-organic frameworks. Chem. Soc. Rev. 2014, 43, 5456-5467.

18. Lalonde, M.; Bury, W.; Karagiaridi, O.; Brown, Z.; Hupp, J. T.; Farha, O. K., Transmetalation: routes to metal exchange within metal-organic frameworks. J. Mater. Chem. A 2013, 1, 5453-5468.

19. Smith, S. J. D.; Ladewig, B. P.; Hill, A. J.; Lau, C. H.; Hill, M. R., Post-synthetic Ti Exchanged UiO-66 Metal-Organic Frameworks that Deliver Exceptional Gas Permeability in Mixed Matrix Membranes. Sci. Rep. 2015, 5, 7823.

20. Hon Lau, C.; Babarao, R.; Hill, M. R., A route to drastic increase of $\mathrm{CO}_{2}$ uptake in $\mathrm{Zr}$ metal organic framework UiO-66. Chem. Commun. 2013, 49, 3634-3636.

21. Nguyen, H. G. T.; Mao, L.; Peters, A. W.; Audu, C. O.; Brown, Z. J.; Farha, O. K.; Hupp, J. T.; Nguyen, S. T., Comparative study of titanium-functionalized UiO-66: support effect on the oxidation of cyclohexene using hydrogen peroxide. Cat. Sci. Technol. 2015, 5, 4444-4451.

22. Destefano, M. R.; Islamoglu, T.; Garibay, S. J.; Hupp, J. T.; Farha, O. K., Room-Temperature Synthesis of UiO-66 and Thermal Modulation of Densities of Defect Sites. Chem. Mater. 2017, 29, 1357-1361.

23. Cliffe, M. J.; Wan, W.; Zou, X.; Chater, P. A.; Kleppe, A. K.; Tucker, M. G.; Wilhelm, H.; Funnell, N. P.; Coudert, F. X.; Goodwin, A. L., Correlated defect nanoregions in a metalorganic framework. Nat. Commun. 2014, 5, 4176.

24. Shearer, G. C.; Chavan, S.; Ethiraj, J.; Vitillo, J. G.; Svelle, S.; Olsbye, U.; Lamberti, C.; Bordiga, S.; Lillerud, K. P., Tuned to Perfection: Ironing Out the Defects in Metal-Organic Framework UiO-66. Chem. Mater. 2014, 26, 4068-4071.

25. Fang, Z.; Bueken, B.; De Vos, D. E.; Fischer, R. A., Defect-Engineered Metal-Organic Frameworks. Angew. Chem. Int. Ed. 2015, 54, 7234-7254.
26. Ling, S.; Slater, B., Dynamic acidity in defective UiO66. Chem. Sci. 2016, 7, 4706-4712.

27. Trickett, C. A.; Gagnon, K. J.; Lee, S.; Gándara, F.; Bürgi, H.-B.; Yaghi, O. M., Definitive Molecular Level Characterization of Defects in UiO-66 Crystals. Angew. Chem. Int. Ed. 2015, 54, 11162-11167.

28. Shearer, G. C.; Vitillo, J. G.; Bordiga, S.; Svelle, S.; Olsbye, U.; Lillerud, K. P., Functionalizing the Defects: Postsynthetic Ligand Exchange in the Metal Organic Framework UiO-66. Chem. Mater. 2016, 28, 7190-7193.

29. Bristow, J. K.; Svane, K. L.; Tiana, D.; Skelton, J. M.; Gale, J. D.; Walsh, A., Free Energy of Ligand Removal in the Metal-Organic Framework UiO-66. J. Phys. Chem. C 2016, 120 (17), 9276-9281.

30. Katz, M. J.; Brown, Z. J.; Colon, Y. J.; Siu, P. W.; Scheidt, K. A.; Snurr, R. Q.; Hupp, J. T.; Farha, O. K., A facile synthesis of $\mathrm{UiO}-66, \mathrm{UiO}-67$ and their derivatives. Chem. Commun. 2013, 49, 9449-9451.

31. Yang, D.; Odoh, S. O.; Wang, T. C.; Farha, O. K.; Hupp, J. T.; Cramer, C. J.; Gagliardi, L.; Gates, B. C., Metal-Organic Framework Nodes as Nearly Ideal Supports for Molecular Catalysts: NU-10oo- and UiO-66-Supported Iridium Complexes. J. Am. Chem. Soc. 2015, 137, 7391-7396.

32. Furukawa, H.; Gándara, F.; Zhang, Y.-B.; Jiang, J.; Queen, W. L.; Hudson, M. R.; Yaghi, O. M., Water Adsorption in Porous Metal-Organic Frameworks and Related Materials. J. Am. Chem. Soc. 2014, 136, 4369-4381.

33. Kapilashrami, M.; Zhang, Y.; Liu, Y.-S.; Hagfeldt, A.; Guo, J., Probing the Optical Property and Electronic Structure of $\mathrm{TiO}_{2}$ Nanomaterials for Renewable Energy Applications. Chem. Rev. 2014, 114, 9662-9707.

34. Scanlon, D. O.; Dunnill, C. W.; Buckeridge, J.; Shevlin, S. A.; Logsdail, A. J.; Woodley, S. M.; Catlow, C. R. A.; Powell, M. J.; Palgrave, R. G.; Parkin, I. P.; Watson, G. W.; Keal, T. W.; Sherwood, P.; Walsh, A.; Sokol, A. A., Band alignment of rutile and anatase $\mathrm{TiO}_{2}$. Nat. Mater. 2013, 12, 798 .

35. Walsh, A.; Butler, K. T.; Hendon, C. H., Chemical principles for electroactive metal-organic frameworks. MRS Bull. 2016, 41, 870-876.

36. Nasalevich, M. A.; Hendon, C. H.; Santaclara, J. G.; Svane, K.; van der Linden, B.; Veber, S. L.; Fedin, M. V.; Houtepen, A. J.; van der Veen, M. A.; Kapteijn, F.; Walsh, A.; Gascon, J., Electronic origins of photocatalytic activity in do metal organic frameworks. Sci. Rep. 2016, 6, 23676.

37. Schrauben, J. N.; Hayoun, R.; Valdez, C. N.; Braten, M.; Fridley, L.; Mayer, J. M., Titanium and Zinc Oxide Nanoparticles Are Proton-Coupled Electron Transfer Agents. Science 2012, 336, 1298-1301.

38. Dan-Hardi, M.; Serre, C.; Frot, T.; Rozes, L.; Maurin, G.; Sanchez, C.; Férey, G., A New Photoactive Crystalline Highly Porous Titanium(IV) Dicarboxylate. J. Am. Chem. Soc. 2009, 131, 10857-10859.

39. Kuznetsov, A. I.; Kameneva, O.; Bityurin, N.; Rozes, L.; Sanchez, C.; Kanaev, A., Laser-induced photopatterning of organic-inorganic $\mathrm{TiO}_{2}$-based hybrid materials with tunable interfacial electron transfer. Phys. Chem. Chem. Phys. 2009, 11, 1248-1257.

40. Ramesha, G. K.; Brennecke, J. F.; Kamat, P. V., Origin of Catalytic Effect in the Reduction of $\mathrm{CO}_{2}$ at Nanostructured $\mathrm{TiO}_{2}$ Films. ACS Catal. 2014, 4, 3249-3254. 
Table of Contents Graphic

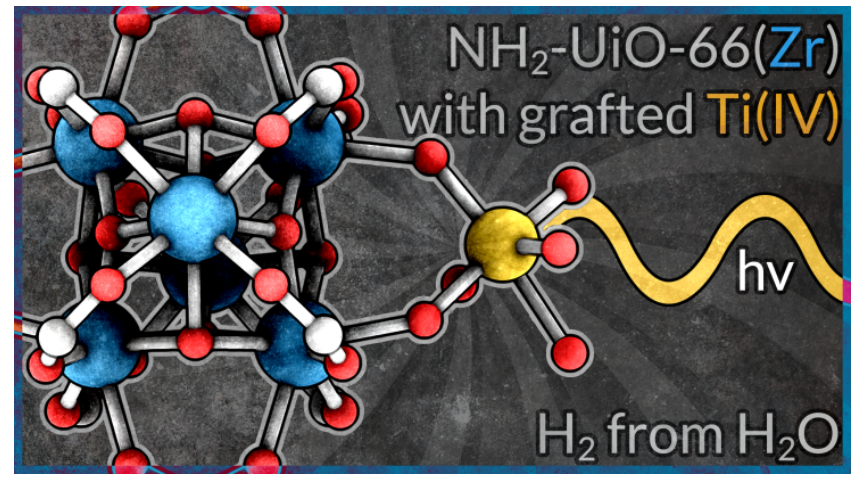

